\title{
Peer mediation - conflict management in a class of its own
}

\section{Alec Coakley}

\section{Abstract}

Peer mediation is a process whereby students learn how to manage conflict for themselves. Peer mediation theory recognises that some conflict in young people's lives can be resolved with the help of other students and so provides the tools of conflict resolution without imposing solutions. Implemented correctly, peer mediation can promote positive influences on school cultures, improve learning environments and enhance student development. This article aims to provide an overview of the practical implementation aspects involved in setting up a peer mediation programme. It will outline some theoretical concepts of peer mediation, describe the curricular context in Ireland through which programmes can be integrated and the types of programme suited to primary and secondary schools. It will also make some key recommendations for future research and the development of peer mediation in Ireland.

\section{Keywords}

Peer mediation, conflict management, school-based conflict, education, dispute resolution

\section{Introduction}

Peer Mediation is an ADR (Alternate Dispute Resolution) process which aims to address school-based conflict in a constructive way. Often described as 'conflict resolution for school children, by school children', participant experiences are 
generally very favourable, with school management, staff and students reporting a wide range of positive outcomes (Gunduz et al., 2017; Tzuriel and Caspi, 2017; O'Toole and Hayes, 2019). Research into the impact of peer mediation, not only on both school life and student development, but also democratic society in general, continues to grow internationally (Schellenberg et al., 2007; Sellman, 2008; Noaks and Noaks, 2009; Harjusola-Webb et al., 2012; Hagel and Brooks, 2013; Corish, 2016; Cremin and Bevington, 2017).

Interestingly, despite this research and subsequent curricular provision for peer mediation and other school-based ADR programmes such as restorative practice, there are very few active peer mediation programmes in Ireland.

This article seeks to bring peer mediation and its potential for positive societal change to the attention of the Irish education and mediation communities and those in a position to advocate for its development as part of a wider national education strategy. It is primarily aimed at academic interest and reviews two complementary approaches in peer mediation literature while positioning these theories in the context of the Irish educational framework.

\section{School-based conflict}

School-based conflict is unique in many ways. It is often physical, with bystanders playing a larger role in whether the conflict escalates (cheering and encouraging, watching conflict from an entertainment point of view) or deescalates (getting help, intervening) (Sellman, 2008). It can be either interpersonal or related to the cultural and organisational attributes of the school (Saiti, 2014).

School-based conflict responses usually place school staff in arbitrator-type roles acting 'in loco parentis' - making real-time, on-the-spot decisions and judgments on student behaviour. There are a number of reasons why this approach may not resolve the issue satisfactorily, including;

- There may be time constraints on achieving an acceptable resolution

- The students might not describe the issues clearly

- The teacher might not fully understand or appreciate the issues 
(Sellman, 2008)

In addition, the arbitrative model offers little scope to school staff to use the conflict to help their students to learn and develop.

Alternatives to arbitration, such as peer mediation and restorative practices, have become increasingly popular as they offer opportunities for students and teachers to learn from the conflict experience (Johnson and Johnson, 1996; Burrell et al., 2003; Baginsky, 2004; Cremin, 2007; Celeste and Buller, 2013).

Prescribed school-based conflict responses in Ireland

The dominant model of school-based conflict management operates through the effective use of governance policies and procedures. In Ireland, legal responsibility for the management of school-based conflict lies with the school boards of management. The duty of care the state provides to protect students in its care is secured in national and European law, this guardianship administered by determination through appointed custodians, teachers and school management. Section 23 of the Education (Welfare) Act 2000, made it a requirement for Irish schools to prepare and make available codes of behaviour for their students.

In December 2005, a group comprised of teachers and principals, law experts and child psychology experts were appointed by the Department of Education \& Science to the National Educational Welfare Board to draw up the first national guidelines for school codes of behaviour. The document 'Developing a Code of Behaviour: Guidelines for Schools' (National Educational Welfare Board, 2008), was issued to help schools prepare these codes of behaviour. The Behavioural Codes of Conduct developed by schools using these guidelines have a legal basis and are supported by fifteen statutes and legislative instruments, including the Irish Constitution, the European Convention on Human Rights and the UN Convention on the Rights of the Child.

'Developing a Code of Behaviour: Guidelines for Schools' is an ambitious, aspirational document with a dual purpose. At one level, the document aims to 
provide each Board of Management with a clear template for the preparation of an effective code of behaviour for its school. At another level, the document seeks to stimulate general discussion and reflection among teachers, staff, students and parents about behaviour policy in their school.

The document has several elements that resonate with ADR theory and practice. The formal nature of behaviour management is not overtly expressed past the legal requirement for it. It validates the formal legislative-arbitrative approach while leaving room for structured, managed informal mediative and restorative processes. It also expressly recommends the use of peer mediation and restorative justice practices in its guidance on disciplinary issues associated with student suspension and expulsion.

\section{Peer mediation}

Peer mediation is a process whereby disputes are resolved through the use of mediators who are of a similar age, gender or social group. When embraced by school communities, peer mediation can strengthen student voice and promote positive behaviours both between students and between staff and students. It can encourage and sustain democratic citizenship and social inclusion (Cremin, 2007). Applied in schools and universities, it has a dual benefit in that as well as addressing school-based conflict management needs, it can educate students about the nuanced nature of social conflict. It can challenge school populations to reconsider the attitudes, philosophies, structural and cultural factors that are the cause of conflict (Cremin and Bevington, 2017).

Peer mediation can offer a student-centred approach to real conflict experiences, an opportunity to learn about conflict as a natural life condition, and a positive force that can stimulate personal growth and social change (Schrumpf et al., 1997). It has also been used effectively to enhance moral development in children and promote their ability to handle hypotheses, abstract concepts and modern problem-solving techniques (Cremin, 2007). 
The development of peer mediation

Peer mediation as currently practiced began in the United States with the peace movement of the late 1960s. The Quakers 'Children's Project for Friends' was one of the first ADR programmes to teach principles of non-violence in New York schools (Sellman, 2008). In the early 1980s, an increased enthusiasm for the use of ADR processes in public areas led to a small group of community mediators and educators forming the National Association for Mediation in Education (Cremin, 2007). This movement quickly spread to Canada, Australia, New Zealand and Europe (Celeste and Buller, 2013).

The United Kingdom has had a widespread and successful experience of peer mediation programme implementation and development through groups such as the Peer Mediation Network (www.peermediationnetwork.org.uk), Conflict Resolution Education in Sheffield Schools Training (CRESST) (www.cresst.org.uk) and Peaceworks (www.peaceworks.org.uk).

Research on peer mediation is overwhelmingly positive in relation to efficacy and student satisfaction (Burrell et al., 2003), with many studies indicating success rates above $90 \%$ (Turnuklu et al., 2009). Peer mediation has been shown to decrease the instances of violence in schools where cultural divisions sparked verbal and physical conflict (Schellenberg et al., 2007).

Research has also shown that peer mediation helps to develop positive behaviours in young children with autism and intellectual disabilities (HarjusolaWebb et al., 2012). It has allowed students to deal constructively with interpersonal conflicts, cultural differences, intimidation, hostility and feelings of disconnectedness (Schrumpf et al., 1997).

\section{A student-centred approach}

School climates where children feel safe, connected and valued have a positive effect on student achievement and reduce instances of emotional distress and violent behaviour (Molnar-Main, 2014). The primary purpose of peer mediation 
is to improve students' lives. It focuses on the needs, issues and potential resolutions that have meaning for the students themselves. It defines the relevant conflict issues, problems and solutions contemporaneously and in ways that are readily understood by the disputants' peers.

\section{Table 1 Advantages of a student-centred peer mediation programme}

Students are able to connect with their peers in ways adults cannot

Peer mediators are able to frame disputes from the perspective of young people and in the language they use, reflecting their attitudes and making the process age-appropriate.

Students perceive peer mediation as a way to talk out problems without fear that an adult authority will judge their behaviours, thoughts or feelings

Peer mediators are respected because they honour the problem-solving process and their peers in the dispute by the way they conduct mediation sessions

The self-empowering aspect of the process appeals to youth and fosters selfesteem and self-discipline

When students come up with their own solutions, they feel in control of their lives and committed to the plans of action that they have created to address their problems.

(Stacey and Robinson, 1997)

Furthermore, the process is contextually aligned with the needs of the student and his or her school-life and activities. It is tailored towards sustainability, manageability and concepts of natural justice. Agreements that have been brokered by students in this way tend to enjoy support not only from the participants themselves but also the wider school community.

The success of these agreements and the language that defines them can diffuse into the school playground, staff room or sports hall (Johnson and Johnson, 1996; Baginsky, 2004; Noaks and Noaks, 2009). It can permeate into how social groups both within and outside of the school communicate with and relate to one another. It can make an impression at home, between parents and siblings 
(Johnson, Johnson and Dudley, 1992). By centring the approach on the individual student, the whole community benefits.

\section{Curricular provision: social, personal and health education}

Curricular provision for school-based ADR systems already exists in Ireland, particularly in relation to peer mediation, as part of the Social, Personal and Health Education (SPHE) curriculum, introduced in 2000. This curriculum aims to provide “. . . particular opportunities to foster the personal development, health and well-being of the individual child, to help him/her to create and maintain supportive relationships and become an active and responsible citizen in society." (Curriculum Committee for Social, Personal and Health Education 1999, p2) The curriculum is intended to support programmes that will contribute "to the development of personal attributes and skills, such as learning how to manage feelings, how to resolve conflicts and how to cope with new and demanding situations."(ibid)

SPHE goals suited to peer mediation

The SPHE curriculum is a comprehensive and ambitious document that considers a wide range of conflict-awareness concepts. A selection of the SPHE curriculum objectives that could potentially benefit from peer mediation are set out in Table 2 below.

Table 2 SPHE objectives that could potentially benefit from peer mediation To develop concepts of self -identity, self-awareness and self-confidence To enable individuals to recognise and appreciate that each person is a unique individual and that this individuality is expressed in many different ways.

To develop the ability to express personal opinions, thoughts and ideas and listen to, respect, think about and comment critically and constructively on the views of others.

To enable individuals to become more independent and autonomous.

To identify situations and places that may threaten personal safety (e.g. bullying) identify sources of help in solving problems (e.g. a parent or guardian, 
a trusted friend, a teacher).

To discuss and identify behaviour that is important for harmony in family life, adhering to family rules, resolving conflict, forgiving, laughter, love, empathy, trust, listening, honesty, accountability, respecting each other.

To consider problems that can arise in friendships and other relationships and how these could be handled (jealousy, uncertainty, feeling left out, pressure to belong and conform).

To recognise, discuss and understand bullying and its effects.

To understand what behaviour constitutes bullying, how and why bullying happens, how it feels to be intimidated and to intimidate others and the effect of bullying on self and others.

To know that bullying is always wrong, explore and discuss how individuals can deal with being bullied, knowing that others are being bullied and being a bully.

To know who to confide in, when to tell, how to be assertive.

To listen actively to others and respect what each person has to say, listening carefully to the experiences and views of others, reflecting and repeating what has been said.

To know and understand the benefits from giving and receiving of compliments and affirmations and giving and receiving constructive criticism.

To begin to appreciate the importance of maintaining a personal stance while also respecting the beliefs, values and opinions of others.

To find positive ways of expressing views that differ from others.

To resolve conflict, to discuss how conflict can arise with different people and in different situations.

To identify and discuss various responses to conflict situations, such as submission, negotiation, aggression, telling the truth, avoidance, walking away

To explore and practise how to handle conflict without being aggressive. Based on the SPHE Curriculum, 1999, p53-63

\section{Peer mediation methodologies}

The introduction of a peer mediation programme to a school should involve careful planning. Two early important considerations are the format of the programme to be implemented and the process by which it will integrate into existing school policies. 
Programme format

The literature describes two main perspectives around which peer mediation programmes can be designed - the 'whole-school approach' and the 'cadre approach'(Johnson and Johnson, 1996). Each of these programmes takes approximately 10 to 15 hours per year and involves learning about interpersonal conflict, active listening, paraphrasing, reframing, and role playing (Burrell et al., 2003).

The 'whole-school' approach

The 'whole-school approach' is a curricular-based conflict prevention model that seeks to train every student in a particular school or class on how to manage conflict constructively through a sequenced progression of workshops. Hypothetical mediation roleplay sessions are acted out by the students themselves and the progress of these sessions then becomes the subject of debate and speculation. It is particularly suitable to senior primary school children, raising their awareness and understanding of conflict. Through navigating these roleplays the students develop the skills, language and strategies of conflict resolution that will potentially assist them in later life.

This programme design thus aims at introducing students, and teachers as co-learners, to regular workshops where a particular type of conflict such as relationship issues, ostracisation or bullying are explored in a safe, structured, supported learning environment;

“. . . these [whole-school programmes] are designed to teach students about conflict and alternatives to violent conflict resolution and are preventative in nature (social skills, empathy training, stress and anger management, attitudes about conflict, bias awareness)."

(Johnson and Johnson, 1996 p460)

The purpose of the whole-school approach is one of organisational learning, education through experience, reflection, understanding and insight. It is primarily 
preventative in nature through the incorporation of the concepts and language associated with conflict resolution into the school language and culture.

The 'whole-school' approach to school-based conflict benefits the whole school - from school culture, to staff and student wellbeing and from behaviours to learning environments. It prevents school-based conflict in two fundamental ways. The first way is by creating a culture of conflict awareness, where the school as a community develops a general appreciation for the nature, mechanics and dynamics of conflict.

The second way it prevents school-based conflict is through the development of a culture of conflict acumen and responsiveness, where conflict, when it does arise, is quickly de-escalated and diverted into pathways that can produce co-created resolutions. This type of peer mediation programme is meant to be enjoyable and interesting. The programme can create interest outside of the programme itself and create interest in conflict resolution in staff rooms, parentteacher meetings and the schoolyard. Posters and exhibits on topics covered can become talking points for other students and staff. In this way the diffusion of conflict management skills and strategies into the school population and culture increases the likelihood of effective and timely interventions by peers, bystanders and school staff that can de-escalate conflict before it becomes an issue.

'Whole-school' implementation need not be as logistically daunting for school administrators as it may seem. It can by rolled out in one particular year (e.g. $5^{\text {th }}$ or $6^{\text {th }}$ class), these students having monthly hour-long peer mediation sessions for that year in that class. A typical year might then involve ten sessions spread over the two terms. This should also ensure the programme is not too onerous on other school activities and allow the students to time to absorb the learning outcomes from each session. Anchoring the programme in a particular year ensures all students will get to experience the programme as they pass through that year. 
The 'cadre-approach'

The 'cadre approach' represents a more direct response model to actual school-based conflict and is suited to schools where there is an identified need for better conflict resolution mechanisms or where there has been an unsatisfactory number of negative experiences of school-based conflict.

It describes a conflict intervention model where a small group of students are selected, mentored and trained to serve as peer mediators for a wider school community (Johnson and Johnson, 1996). The approach helps older children and teenagers explore actual conflict experiences positively, safely and constructively among their peers, assisted through governance measures implemented by school management.

In this model a volunteer cadre or response team of students is developed, resourced, trained and supported by school management as part of a broader conflict management strategy. The team works with school management in a collaborative model that aims to reduce the instances and effects of school-based conflict. This might mean regular meetings of the cadre and school management to discuss conflict generally in the school and the types of measures that could be implemented to prevent it and deal with it when it happens. Are there problems integrating new students? Are there resource challenges? Are there particular flashpoints or patterns? Is the code of behaviour understood and observed? What pro-active measures might help this? Can some conflict be peer mediated? If so what type of framework might be need to be put around that activity?

The size, composition and management of the cadre is critically important to the success of the programme. This can be a problem for programme administrators. Criticisms of peer mediation programmes based on this approach relate to the methods by which the cadre members are selected and the inequalities that can arise when selection processes seem biased (Baginsky, 2004).

In some cases the student body selects the cadre, or the cadre is selected based on a set of criteria prescribed by the student body (Turnuklu et al., 2009). 
Fetzer (2014) describes a particularly problematic peer mediation programme implementation in an 'alternative school' in Utah as a public relations exercise, a method of student surveillance and a tool through which administrators could "marginalize the students of color from the White students of privilege" (Fetzer, 2014, p86).

Flecknoe (2005), posits that peer mediator selection can reflect the power structures in the school, favouring students who exhibit leadership potential. Students who "do not fit in with the system are almost universally ignored in cadre selection" (p224). Bickmore (2002), stresses the importance of having programme administrators who demonstrate a strong commitment and clear purpose to potential peer mediators. She highlights the need to ensure that the peer mediators understand the limitations and parameters through which they are expected to work and the need to understand too the differences between mediation and traditional patterns of discipline management, In her study she notes:

"School staff reported improvements in self- discipline, attitude toward school, and communication skills, particularly among those they had considered to be less successful or troublesome students. Some schools were far more successful than others in keeping diverse students - especially those originally seen as 'negative leaders' and those with limited English- as active and confident members of the conflict management program. The most important factor was the commitment and capacity of the program advisors to coach and encourage the whole range of students, and regular/frequent mediator meetings."

(Bickmore, 2002, p. 36)

As part of the initial recruitment process for a peer mediation programme in North Carolina, Norma Day-Vines and her fellow coordinators issued personal invitations to students from less well-represented groups in an effort to ensure as much diversity in their peer mediation cadre as possible (Day-Vines et al., 1996). These received positive responses, attributable, the authors believe, to the warmth and sincerity of the invitations. They urge caution when selecting for 
diversity, however, concluding that cadre heterogeneity should reflect the school population as a whole. They note that the process of cadre recruitment, selection and training will give rise to tensions within the cadre itself, symptomatic of the larger tensions within the student body. They note also that this can have positive consequences, exposing the peer mediators to differing perspectives and developing their repertoire of skills.

Online peer mediation using the cadre approach

The cadre approach is also suited to remote mediation through the use of video conferencing technologies such as Zoom ${ }^{\circledR}$ and Skype ${ }^{\circledR}$. In the United States, recent advances in video technology and availability have enabled some of these peer mediation cadres to mediate conflicts in other schools, and sometimes with students in the privacy of their own homes. Inspired by the prevalence and student preferences for technologically supported communication, a two-year online peer mediation training project conducted in 2015 by the Online Peer Mediation Platform (OPMP) and the National Association of Peer Program Professionals (NAPPP, www.peerprogramprofessionals.org) was well received by participants (Tindall, 2016).

Using this technology, trained peer mediators in one school can assist in resolving conflict in other schools where such programmes do not exist. These social-media contemporary advances herald a new direction for this particular model of peer mediation that will undoubtedly continue to receive attention from education and mediation researchers.

Cadre programme integration

Cohen (1995) describes a useful integration philosophy where only the most serious conflicts end up being arbitrated by school staff as represented in Figure 1 below. 


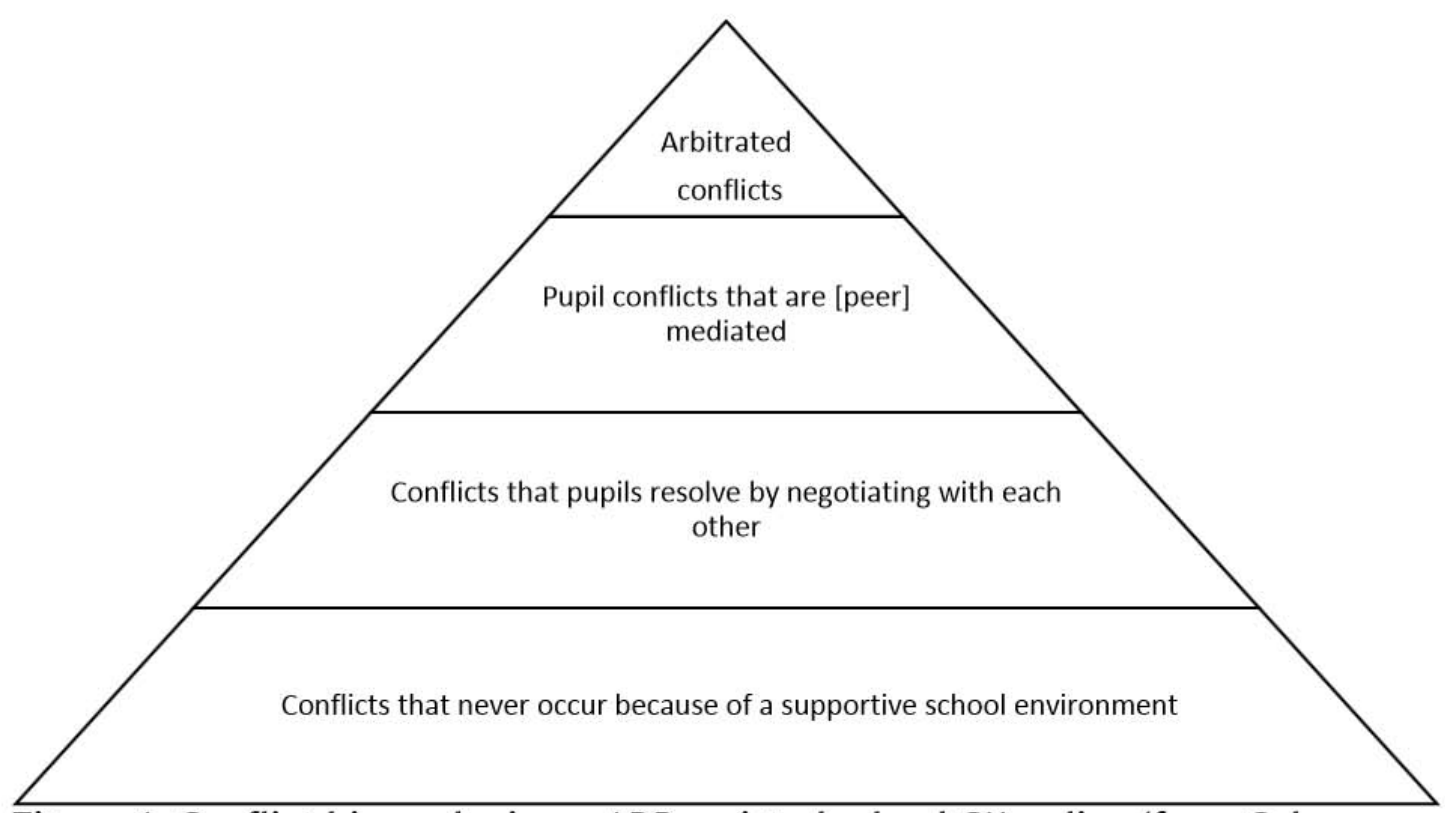

Figure 1 Conflict hierarchy in an ADR assisted school CM policy (from Cohen (1995))

Cohen's pyramid provides a solid basis for any cost-benefit analysis the school management may wish to undertake, as it suggests that a significant reduction in the amount of conflict being managed through traditional methods can be expected. This also suggests an ethical question. If students will be doing the work that should be the responsibility of teachers and principals, how is that to be viewed by those involved and the wider school community?

In the integration process, school management might also decide to form a cross-functional, stakeholder group to help with the initial implementation and afterwards with ongoing review measures. Steering committees and/or advisory groups supported by regular reflection and review meetings can help build confidence in new arrangements (Lalor, 2017). These groups can include “administrators, disciplinarians, students, teachers, people from sponsoring agencies, parents, and perhaps even community members involved with juvenile justice or human services" (Cohen, 1995, p79). They can provide a useful forum to iron out difficult issues, offer emotional, technical and logistical support during frustrating challenges, act as a sounding board for new ideas or problem-solving exercises, and help with objective evaluations of the programme. 
Cadre conflict suitability protocols

Peer mediation programmes should be viewed as complementary to traditional school-based conflict management policies and procedures. The decision to introduce ADR-based programmes should also take account of the available school resources required to maintain it. There needs to be a synergy between the philosophy of mediation and the existing or developing culture in the school (Sellman, 2008).

This also means that peer mediation programmes should not be considered appropriate for instances of serious conflict, conflict of a sensitive nature (e.g. pertaining to family issues, religion or sexuality) or conflict where the school itself or other parties might be involved. These types of conflict should be dealt with through the normal protocols within the school management structure. It is in everyone's interest that these principles are known and respected and placing suitable governance boundaries around peer mediation programme operational terms of reference is essential to their success.

A pre-mediation session discussion involving a school management representative should always be held before peer mediation takes place to decide whether a particular issue is appropriate for peer mediation. This discussion should focus on evaluating an accurate risk assessment posed by the type of conflict in question and the ability and willingness of the peer mediators to mediate the issue.

Cohen (1995) describes issues that violate a school policy and warrant disciplinary action rather than attempts at peer mediation. These include conflicts over drugs or weapons or arising out of verbal abuse, where there is a potential for violence or where the programme administrators believe either party is unwilling to take the process seriously.

These considerations are consistent with issue suitability findings by Baginsky (2004) and Schrumpf et al. (1997), outlined in Table 3 below. 
Table 3 A selection of types of conflict and their suitability for peer mediation

\begin{tabular}{|l|l|}
\hline Suitable for peer mediation & Unsuitable for peer mediation \\
\hline Allegations of bullying & Serious bullying or cyberbullying \\
\hline Instances of name-calling, insults and threats & Family matters \\
\hline Friendship issues & Breaking the law \\
\hline Ostracisation & School rules or property \\
\hline Child has experienced something unfair & Violent incidents \\
\hline Being picked on or teased & Sexual assault \\
\hline $\begin{array}{l}\text { Harassment based on race, class, gender or } \\
\text { sexual orientation }\end{array}$ & $\begin{array}{l}\text { Incidents involving vulnerable } \\
\text { people }\end{array}$ \\
\hline
\end{tabular}

developed from Baginsky (2004) and Schrumpf et al. (1997)

\section{Conclusion}

Peer mediation is an intervention and prevention conflict management process that can benefit school environments and student development. Irish government policy on conflict management in education as outlined in the Developing a Code of Behaviour: Guidelines for Schools and the SPHE curriculum allows for the introduction of peer mediation programmes in schools within an aligned conflict management framework, specifically in relation to disciplinary measures.

The literature outlines two models in which peer mediation can be successfully integrated into schools - a preventative, curricular approach focused on learning and awareness about conflict and how to navigate it which suits primary school students and another responsive, skills-based, active approach that involves real conflict issues and which is suited to older students in secondary schools and third-level education. 
Careful use of these methods could deliver many of the anticipated benefits to students and schools in Ireland. Peer mediation is still in its infancy in Ireland but as programmes develop, students may seek out the skills required to manage conflict for themselves, furthering development in this area of education. More interest in this area will create opportunities for much-needed research in an Irish context.

Important research gaps in this area include, for example, the use of peer mediation in Special Educational Needs (SEN), potential adaptations into thirdlevel education, student impressions of mediation, the effect of peer mediation on gender and diversity issues, student perspectives on the nature of conflict and the longer-term effect of peer mediation on student outcomes.

Starting secondary school can be a traumatic transition for children. Participating in a peer mediation programme in the final year of primary school can be a good preparation for the changes ahead. Empirical studies on how the two models outlined here can be made to dovetail into each other would be of significant interest. Similarly, research could be done on the transition from secondary school to third-level education.

Finally, the potential for diffusion of these programmes into families, communities and workplaces and the effects this may have on conflict in those sectors, would help inform further intersectional development in ADR theory.

\section{References}

Baginsky, W. (2004) Peer mediation in the UK: a guide for schools. National Society for the Prevention of Cruelty to Children.

Bickmore, K. (2002) 'Good Training is Not Enough: Research on Peer Mediation Program Implementation.', Social Alternatives, 21(1), p. 33.

Burrell, N. A., Burrell, N. A., Zirbel, C. S. and Allen, M. (2003) 'Evaluating peer mediation outcomes in educational settings: A meta-analytic review', Conflict Resolution Quarterly, 21(1), pp. 7-26. doi: 10.1002/crq.46. 
Celeste, A. and Buller, P. (2013) 'Peer Mediation in United States High Schools', in. Scholarship \& Creativity Day, College of Saint Benedict, St. Joseph, MN. Available at: https://digitalcommons.csbsju.edu/peace_studies_students/1/ (Accessed: 19 February 2020).

Cohen, R. (1995) Students Resolving Conflict: Peer Mediation in Schools. Glenview, IL. Good Year Books.

Corish, M. (2016) 'How peer mediation empowers children to build self-esteem', How peer mediation empowers children to build self-esteem, 8 September. Available at: http://www.ashoka.ie/media/2016/9/8/peer-mediation (Accessed: 17 March 2017).

Cremin, H. (2007) Peer Mediation: Citizenship And Social Inclusion Revisited: Citizenship and Social Inclusion in Action. Maidenhead: McGraw-Hill Education (UK).

Cremin, H. and Bevington, T. (2017) Positive Peace in Schools: Tackling Conflict and Creating a Culture of Peace in the Classroom. Oxford: Routledge. Curriculum Committee for Social, Personal and Health Education (1999) Social, personal and health education: Curriculum. National Council for Curriculum and Assessment. Dublin: Stationery Office.

Day-Vines, N. L., Day-Hairston, B. O., Carruthers, W. L., Wall, J. A. and LuptonSmith, H. A. (1996) 'Conflict Resolution: The Value of Diversity in the Recruitment, Selection, and Training of Peer Mediators', The School Counselor, 43(5), pp. 392410.

Fetzer, M. (2014) A Critical Case Study of Peer Mediation at an Alternative High School. Doctoral dissertation. Department of Education, Culture and Society, University of Utah. Available at:

https://pdfs.semanticscholar.org/f39e/0b1bf5b084d918fa3f3541bdd6a9d47b67c4.p df (Accessed: 19 February 2020).

Flecknoe, M. (2005) 'What does anyone know about peer mediation?', Improving schools, 8(3), pp. 221-235.

Gunduz, N., Uzunboylu, H. and Ozcan, D. (2017) 'Developing and testing a scale to assess teachers' attitudes toward peer mediation of student disputes', Social Behavior and Personality, 45(10), pp. 1745-1760. doi: 10.2224/sbp.6798. 
Hagel, S. and Brooks, E. (2013) 'Peace-building through Peer Mediation', Teaching Citizenship, pp. 13-14.

Harjusola-Webb, S., Hubbell, S. P. and Bedesem, P. (2012) 'Increasing Prosocial Behaviors of Young Children With Disabilities in Inclusive Classrooms Using a Combination of Peer-Mediated Intervention and Social Narratives', Beyond Behavior, 21(2), pp. 29-36.

Johnson, D. W. and Johnson, R. T. (1996) 'Conflict resolution and peer mediation programs in elementary and secondary schools: A review of the research', Review of Educational Research, 66(4), pp. 459-506.

Johnson, D. W., Johnson, R. T. and Dudley, B. (1992) 'Effects of Peer Mediation Training on Elementary School Students.', Mediation Quarterly, 10(1), pp. 89-99. Lalor, T. (2017) 'Peer Mediation Pilot Initiative in Castlerea Prison: A Process Evaluation', Journal of Mediation \& Applied Conflict Analysis, 4(2).

Molnar-Main, S. (2014) Integrating Bullying Prevention and Restorative Practices in Schools: Considerations for Practitioners and Policymakers. Center for Safe Schools, Clemson Institute on Family and Neighborhood Life, Highmark Foundation. Available at:

http://www.safeschools.info/content/BPRPWhitePaper2014.pdf (Accessed: 19 February 2020).

National Educational Welfare Board (2008) Developing a Code of Behaviour: Guidelines for Schools. Available at:

http://www.tusla.ie/uploads/content/guidelines_school_codes_eng.pdf (Accessed: 3 January 2017).

Noaks, J. and Noaks, L. (2009) 'School-based peer mediation as a strategy for social inclusion', Pastoral Care in Education, 27(1), pp. 53-61.

O'Toole, L., and Hayes, N. (2019) Supporting positive behaviour in early childhood settings and primary schools : relationships, reciprocity, and reflection. Online. Routledge. Available at: https://www-taylorfranciscom.jproxy.nuim.ie/books/9781315098845 (Accessed: 19 February 2020). Saiti, A. (2014) 'Conflicts in schools, conflict management styles and the role of the school leader: A study of Greek primary school educators', Educational Management Administration \& Leadership, 43(4), pp. 582-609. doi:

$10.1177 / 1741143214523007$. 
Schellenberg, R., Parks-Savage, A. and Rehfuss, M. (2007) 'Reducing levels of elementary school violence with peer mediation', Professional school counseling, 10(5), pp. 475-481.

Schrumpf, F., Crawford, D. K. and Bodine, R. J. (1997) Peer mediation: conflict resolution in schools: program guide. Champaign, Illinois: Research Press Co. Sellman, E. (2008) Mediation matters: creating a peaceful school through peer mediation. Cambridge: LDA.

Stacey, H. and Robinson, P. (1997) Let's Mediate: A Teachers' Guide to Peer Support and Conflict Resolution Skills for All Ages. SAGE.

Tindall, J. (2016) 'Online peer mediation platform: taking peer mediation to the next level', Online Peer Mediation Project. Available at: https://www.mediate.com/articles/OnlinePeer.cfm (Accessed: 6 August 2019). Turnuklu, A., Kacmaz, T., Sunbul, D. and Ergul, H. (2009) 'Does peer-mediation really work? Effects of conflict resolution and peer-mediation training on high school students' conflicts', World Conference on Educational Sciences: New Trends and Issues in Educational Sciences, 1(1), pp. 630-638. doi:

10.1016/j.sbspro.2009.01.112.

Tzuriel, D. and Caspi, R. (2017) 'Cross-generational transmission of teaching strategies: The moderating role of peer-mediation', Journal of applied developmental psychology, 52, pp. 138-148. doi: 10.1016/j.appdev.2017.07.006.

Alec Coakley is a certified mediator with the Mediators Institute of Ireland. His first peer mediation programme began in 2013. He now co-ordinates programmes at primary school level and secondary school level, on a voluntary basis, employing both models outlined in the literature. He is currently undertaking a doctoral thesis on conflict and education in the School of Education, Maynooth University. He can be contacted at aleccoakley@gmail.com. 